\title{
Aqueous Preparation of Self-Supported Hydroxypropyl Methylcellulose-Polyaniline Conducting Films and the Evaluation of Their Electrical and Mechanical Properties
}

\section{Vinicius Cavalheiro Maeda}

Universidade Federal de São Paulo: Universidade Federal de Sao Paulo

\section{Cintia Marques Correa}

Universidade Federal de São Paulo: Universidade Federal de Sao Paulo

Marcos Henrique Mamoru Otsuka Hamanaka

Autocoat Equipamentos e Processos de Deposição LTDA

Viviane Nogueira Hamanaka

Autocoat Equipamentos e Procesos de Deposição LTDA

\section{Celso Molina}

Universidade Federal de São Paulo: Universidade Federal de Sao Paulo

Fernanda F Camilo ( $\nabla$ ffcamilo@unifesp.br)

Universidade Federal de São Paulo: Universidade Federal de Sao Paulo https://orcid.org/0000-00022988-1409

\section{Research Article}

Keywords: Polyaniline, hydroxypropyl methylcellulose, conducting paper, cellulose derivative, aqueous preparation

Posted Date: March 2nd, 2022

DOI: https://doi.org/10.21203/rs.3.rs-1347744/v1

License: (c) (i) This work is licensed under a Creative Commons Attribution 4.0 International License. Read Full License 


\section{Abstract}

The purpose of this work was to develop a simple method to produce self-supported and homogeneous films composed of hydroxypropyl methylcellulose (HPMC) and polyaniline (PANI) by the simple mixture of aqueous solutions of both polymers with subsequent drying. The addition of HPMC, a cellulose derivative with an excellent film-forming capacity, was fundamental to overcoming the poor processability of pristine PANI film, which impairs its use in many technological applications. Despite being an insulating polymer, the addition of HPMC did not significantly decrease the conductivity and all hybrid films showed conductivity in the order of $10^{-2}-10^{-3} \mathrm{~S} \mathrm{~cm}^{-1}$, which is in the range for metals or semiconductors. The typical electroactivity of PANI was also maintained with the addition of HPMC. Also, as a beneficial, adding HPMC the thermal stability and the mechanical properties of the pristine PANI were improved. Cellulose-containing conducting polymers with electroactive activity can be considered as a material of the future, with possible applications in several areas, such as smart wallpapers, e-papers, and sensors.

\section{Introduction}

Polyaniline (PANI) is one of the most studied conducting polymers due to its ease of synthesis, low cost, reversible redox properties, and thermal and chemical stabilities(Boeva and Sergeyev 2014). Owing to its desirable features, PANI has been applied in various fields such as sensors, anticorrosion and antistatic coatings, electrochromic displays, and among other applications(Hyodo 1994; Snook et al. 2011; Deshpande et al. 2014; Hong et al. 2020) Although these advantages, PANI is relatively hard to process due to its insolubility in the majority of usual solvents and its poor mechanical strength at high temperatures. PANI cannot be easily cast into films, membranes, molded into different shapes, or extruded into fibers, significantly impairing their use in many technological applications(Bhattacharya and De 1996). To overcome these limitations, the combination of PANI with other polymeric matrices with superior mechanical properties has been proposed. Among these polymers, hydroxypropyl methylcellulose (HPMC) is one of the most attractive, since it is a cellulose derivative, it is water-soluble and it is a good film-forming material with a lot of potential applications(Fahs et al. 2010; Wrona et al. 2017). Despite these productive coupling, the incompatibility of solubility between HPMC and PANI, aiming the formation of conductive films without phase separation, is a drawback to be solved(Hussin et al. 2017). The conductive polymer must be well-dispersed in the matrix so that the passage of electrons would be homogeneous since this process can be discontinued where the conducting polymer is absent(Cho et al. 2004; Liu and Grunlan 2007). Only a few recent studies have explored the preparation of conductive composite based on HPMC and PANI films. In 2020, Kim and coworkers have fabricated flexible composited based on PANI and cellulose fabrics with electrical conductivity in the order of $10^{-2} \mathrm{~S}$ $\mathrm{cm}^{-1}$ (Kim et al. 2020). In 2017, Hussin and colleagues have developed a procedure to produce aqueous PANI-cellulose derivatives dispersions through polymerization of aniline monomer in cellulose solution initiated by ammonium persulphate. After the removal of water, the film showed conductivity around $1.87 \times 10^{-1} \mathrm{~S} \mathrm{~cm}^{-1}$ (Hussin et al. 2017). Later, the same researchers have used the PANI-HPMC composite 
as a chemical sensor for detecting hydrazine in aqueous effluents through the electrical conductivity values variation(Hussin et al. 2021).

This study aims to produce conductive films based on HPMC and polyaniline (Fig. 1) using a very simple procedure. To produce homogenous films, it was used a water-soluble polyaniline solution and an aqueous HPMC solution. The chemical and physical structures, electrical conductivity, mechanical properties of the conductive cellulose film are evaluated.

\section{Materials And Methods}

\section{Materials}

Hydroxypropyl methylcellulose (HPMC) (Vivapur K4M, J. Rettenmaier \& Söhne GmbH + Co KG) was used as purchased. Aqueous solutions of HPMC $(2 \% \mathrm{w} / \mathrm{w})$ were prepared by adding the required amount of polymer to distilled water. This solution was denominated $\mathrm{HPMC}_{-} \mathrm{H}_{2} \mathrm{O}$. Aniline (Aldrich, 99\%) was distilled before the use. Polyvinylpyrrolidone (PVP) (Aldrich, average molecular weight of 360.000 ) and ammonium persulphate (Aldrich, 98\%) were used as purchased.

\section{Preparation of the polyaniline aqueous dispersion}

This dispersion was synthesized following a procedure described in the literature(Stejskal and Sapurina 2005). Firstly, aniline hydrochloride was prepared by mixing aniline $(85 \mathrm{mmol})$ and concentrated hydrochloric acid (85 mmol). It melts at $196-198{ }^{\circ} \mathrm{C}$ (Furst and Moore 1957). Then, an aqueous solution of ammonium persulphate ( $5.71 \mathrm{~g}$ in $50 \mathrm{~mL}$ deionized water; $25 \mathrm{mmol}$ ) was prepared (SOLUTION A). Aniline hydrochloride ( $2.59 \mathrm{mg} ; 20 \mathrm{mmol})$ was dissolved in an aqueous solution of PVP $\left(40 \mathrm{~g} \mathrm{~L}^{-1}\right)$, instead of water, to $50 \mathrm{ml}$ of solution (SOLUTION B). Solution A and B were mixed at room temperature for 10 minutes and then left at rest to polymerize. The polymerization was completed in several minutes (30 minutes). The dispersion was exhaustively dialyzed against $0.2 \mathrm{~mol}^{-1} \mathrm{HCl}$ to remove ammonium sulfate resulting from the decomposition of ammonium persulphate and a potential residual monomer. It was used a dialysis tubing cellulose membrane with a typical molecular weight cut-off of 14.000. A green dispersion was obtained (Fig. 1S).

\section{Fabrication of HPMC-PANI films}

HPMC_ $\mathrm{H}_{2} \mathrm{O}$ solution was mixed with different volumes of the PANI dispersion at room temperature for 15 minutes. Films with distinct amounts of $\operatorname{HPMC}(0,5,10,20,30,40 \mathrm{w} / \mathrm{w} \%)$ were prepared and all amounts used in the preparations are indicated in Table 1. The resulting solutions were transferred into a polystyrene petri dishes (diameter $=8.5 \mathrm{~cm}$ ) and oven-dried at $60^{\circ} \mathrm{C}$ overnight. These films were denoted as PANI_x\%HPMC, where $x$ is the mass percentage of HPMC. All calculations are shown in Note 1 in the Supplementary Information. An illustration of this preparation procedure is shown in Fig. 1S. 
Table 1

Amounts of components used in the PANI_x\%HPMC films*

\begin{tabular}{|lllllllll|}
\hline Nome do Filme & $\begin{array}{l}\text { Mass of } \\
\text { HPMC } \\
\text { solution** } \\
(\mathbf{g})\end{array}$ & $\begin{array}{l}\text { HPMC } \\
\text { mass } \\
(\mathbf{m g})\end{array}$ & $\begin{array}{l}\text { Volume of } \\
\text { PANI } \\
\text { dispersion } \\
(\mathbf{m l})\end{array}$ & $\begin{array}{l}\text { PANI } \\
\text { mass } \\
(\mathbf{m g})\end{array}$ & $\begin{array}{l}\text { PVP } \\
\text { Mass } \\
(\mathbf{g})\end{array}$ & $\begin{array}{l}\text { wt \% } \\
\text { of } \\
\text { HPMC }\end{array}$ & $\begin{array}{l}\text { wt \% } \\
\text { of } \\
\text { PANI }\end{array}$ & $\begin{array}{l}\text { \%wt } \\
\text { PVP }\end{array}$ \\
\hline PANI & 0 & 0 & 19.20 & 416 & 384 & 0 & 52.0 & 48.0 \\
\hline PANI_5\%HPMC & 2.00 & 40 & 18.20 & 395 & 365 & 5 & 49.4 & 45.6 \\
\hline PANI_10\%HPMC & 4.00 & 80 & 17.30 & 374 & 346 & 10 & 46.8 & 43.2 \\
\hline PANI_20\%HPMC & 8.00 & 160 & 15.40 & 333 & 307 & 20 & 41.6 & 38.4 \\
\hline PANI_30\%HPMC & 12.00 & 240 & 13.40 & 290 & 270 & 30 & 36.3 & 33.7 \\
\hline PANI_40\%HPMC & 16.00 & 320 & 11.50 & 250 & 230 & 40 & 31.3 & 28.7 \\
\hline
\end{tabular}

*All calculations are shown in Note 1 (Supplementary Information)

** Aqueous solutions of HPMC $(2 \% w / w)$

Characterization

Thermal analyses (TGA) were carried out on DTG-60 SHIMADZU equipment, using an aluminum crucible, heating rate of $5^{\circ} \mathrm{C} \mathrm{min}^{-1}$, and under a synthetic air flow of $100 \mathrm{~mL} \mathrm{~min}^{-1}$ in a temperature range of 30$900^{\circ} \mathrm{C}$.

Dynamic mechanical analysis (DMA) was performed in a DMA Q800-TA instrument using air atmosphere with bending deformation at a heating rate of $5^{\circ} \mathrm{C} \min ^{-1}$ from 30 to $300{ }^{\circ} \mathrm{C}$ and. The tests were carried out with a fixed frequency of $1 \mathrm{~Hz}, 1 \mathrm{~N}$ applied pre-force and oscillation amplitude of $25 \mu \mathrm{m}$. The films were cut into $6 \mathrm{~mm} \times 40 \mathrm{~mm}$.

For the attenuated reflectance measurements, a horizontal ATR sampling accessory (ATR-8200HA) equipped with ZnSe cell was employed. All spectra were carried out using a SHIMADZU PRESTIGE-21 spectrometer in the range of $4000-700 \mathrm{~cm}^{-1}$ with a $4 \mathrm{~cm}^{-1}$ resolution.

Electronic absorption spectra were recorded in an OCEAN OPTICS spectrophotometer model USB 4000. The films were vertically positioned (perpendicular to the light beam) in a home-made sample-holder. The spectra of each film were measured using the non-irradiated film itself as a blank in order to have the light scattering of the films compensated.

X-rays diffractograms (XRD) were recorded in a BRUKER D8 Advance lab diffractometer using the CuKa radiation $(\lambda=1.54 \AA)$ from a generator operating at $40 \mathrm{keV}$ and $40 \mathrm{~mA}$ as the applied voltage and current. respectively. 
Scanning electron microscopy (SEM) images of the films were registered using a JSM-6610 microscope by JEOL, using secondary electron detection mode with carbon-coated samples. The chemical composition of the samples was determined by energy dispersive X-rays spectroscopy (EDS).

Cyclic voltammetry experiments were performed in a potentiostat (METROHM AUTOLAB model $302 \mathrm{~N}$ ) using a single compartment electrochemical cell. A carbon glass electrode (Metrohm, Geometric area = $\left.0.0314 \mathrm{~cm}^{2}\right)$ was used as working electrode, a Pt wire as a counter electrode, and an $\mathrm{Ag} / \mathrm{AgCl}(\mathrm{KCl} 3 \mathrm{~mol}$ $\mathrm{L}^{-1}$ ) as a reference electrode. These measurements were carried out in different potential windows ranging from $-0.2 \mathrm{~V}$ to $0.8 \mathrm{~V}$ with scan rate $100 \mathrm{mV} \mathrm{s}^{-1}$ in $1.0 \mathrm{M} \mathrm{HCl}$ aqueous solution. The working electrode was modified via drop-casting of four sequential depositions of $10 \mu \mathrm{L}$ of the dispersion followed by drying at $40^{\circ} \mathrm{C}$.

The Zeta potentials of the dispersions were measured in disposable folded capillary cells (DTS1070) in triplicate in a Zetasizer Nano ZS from Malvern.

Tensile strength ( $\mathrm{MPa}$ ) and elongation at break (\%) were measured using a Brookfield CT3 texture analyzer with a dual grip assembly (TA3/100). The preload force was set to $0.07 \mathrm{~N}$ and all tests were performed at a strain rate of $0.05 \mathrm{~mm} / \mathrm{s}$ until the film samples were ruptured. The film samples were cut into rectangle strips $(100 \mathrm{~mm} \times 25.4 \mathrm{~mm})$ and fixed on the grips of the stretching unit. The tensile strength was estimated by dividing the maximum load by cross-sectional area of the film (thickness $x$ width) while the elongation at break was obtained as the percentage of extension at the moment of rupture.

The electrical conductivity measurements were performed in triplicate using a four-point method with a FPP200 equipment at room temperature and $55 \%$ of humidity.

\section{Results And Discussion}

\section{PANI dispersion synthesis}

The aqueous dispersion of polyaniline was prepared by the oxidation of aniline by sulfate persulfate using polyvinylpyrrolidone as a stabilizer, following a well-established procedure described in the literature(Stejskal and Sapurina 2005). The crude product was dialyzed to remove any reaction byproducts and low molecular weight impurities. It was obtained a green dispersion, which is the typical color of the PANI in the emeraldine salt oxidation state (Fig. 1S). The absorption spectrum (Fig. 2) has a broad band located between $300-450 \mathrm{~nm}$ which is characteristic of $\pi-\pi^{*}$ and polaron- $\pi^{*}$ transitions and another between 600 to $800 \mathrm{~nm}$ assigned by the $\pi$-polaron transition. These features confirmed the formation of emeraldine salt form(Trchová et al. 2014). The spectra collected from this sample each week for 2 months were identical, indicating that the dispersion is stable with time. The Zeta potential of the PANI dispersion was $0.64 \pm 0.20 \mathrm{mV}$, suggesting that PVP, a neutral polymer, is responsible for the steric stabilization of this sample(Somani 2003). 
Hydroxypropyl methylcellulose-PANI films were prepared by simple mixing of the aqueous solutions of PANI and HPMC, followed by drying. It was prepared pristine HPMC and PANI films for comparison. The films obtained were self-supported and present green color and they seem homogeneous in appearance to the naked eye (Fig. 3). It is worth mentioning that on closer observation obtained in an electronic microscope this homogeneity is also observed (Fig. 2S).

Aiming to apply the films as conductive materials, the electrical conductivities at room temperature of three different places of the films were measured and the results were obtained by arithmetic average are shown in Table 2. The measurements made in different regions of the films were quite similar, indicating that the samples were homogeneous. The incorporation of PANI as a conductive loading into the HPMC, which is an insulator material, leads to an increase in electrical conductivities. All obtained films can be classified as conductive paper, because the conductivity is around $10^{-3} \mathrm{~cm}^{-1}$, which is in the range for metals or semiconductors(Kelly et al. 2007). Independently of the HPMC loading, the electrical conductivity values of the films are in the same order of magnitude. One explanation for that is based on that the conductive loading (PANI) is homogeneously distributed in the HPMC membrane.

Table 2

Electrical conductivity values of the films.

\begin{tabular}{|ll|}
\hline Sample & Electrical conductivity $\left(\mathrm{S} \mathrm{cm}^{-1}\right)$ \\
\hline HPMC & Insulating material \\
\hline PANI & $17 * 10^{-3} \pm 5.7 * 10^{-4}$ \\
\hline PANI_5\%HPMC & $11 * 10^{-3} \pm 7.3 * 10^{-4}$ \\
\hline PANI_10\%HPMC & $9.1 * 10^{-3} \pm 1.9 * 10^{-4}$ \\
\hline PANI_20\%HPMC & $7.6 * 10^{-3} \pm 2.9 * 10^{-5}$ \\
\hline PANI_30\%HPMC & $6.3 * 10^{-3} \pm 1.6 * 10^{-3}$ \\
\hline PANI_40\%HPMC & $5.4 * 10^{-3} \pm 6.9 * 10^{-4}$ \\
\hline
\end{tabular}

In view of the conductivity results, in further characterizations (FTIR, DRS, TGA, DMA, tensile tests), only the samples with the lowest and highest amount of HPMC and the pristine ones (HPMC and PANI) were used.

PANI film (Fig. 4A) reveals bands at 821, 1157, 1491, 1582-1609 $\mathrm{cm}^{-1}$ (highlighted with green rectangles) attributed to $\mathrm{C}-\mathrm{H}$ (the first three ones) and $\mathrm{C}=\mathrm{C}$ benzenoid and quinonoid $\mathrm{C}=\mathrm{C}$ ring vibrations. The band located at $1350 \mathrm{~cm}^{-1}$ (pointed out with a black arrow) has been assigned to the vibration mode of the C$\mathrm{N}^{+}$structure in the emeraldine salt form of polyaniline.(Stejskal and Sapurina 2005) In addition, the typical bands of PVP are seen at 1291, 1424 e $1656 \mathrm{~cm}^{-1}$ (highlighted with magenta rectangles) associated with the C-N stretching, C-H bending, and C = O stretching.(Koczkur et al. 2015) The FTIR 
spectrum of the pristine PVP film was shown in the inset of Fig. 4 for comparison. The carbonyl stretching band observed in the PVP at $1660 \mathrm{~cm}^{-1}$ suffers a slight change in the PANI sample, suggesting the interaction of this functional group with the $\mathrm{N}-\mathrm{H}$ bonds (e.g.) present in the PANI structure, as previously reported in the literature(da S. Oliveira et al. 2018).

FTIR spectrum of HPMC film (Fig.4D) exhibits absorptions related to the C-O axial deformation around 1060 e $941 \mathrm{~cm}^{-1}$ and $\mathrm{C}-\mathrm{H}$ stretching bands in the range of $2800-2900 \mathrm{~cm}^{-1}$. Bands at wavenumbers around 1369 e $1452 \mathrm{~cm}^{-1}$ are assigned to the angular deformation of $\mathrm{C}-\mathrm{H}$ bonds within $\left(\mathrm{CH}_{2}\right)_{\mathrm{n}}$ chains. The bands close to 1639 e $3455 \mathrm{~cm}^{-1}$ are related to the angular and axial deformations of the residual hydroxyl groups or adsorbed water, present in the HPMC film, respectively.(Bhatti et al. 2013)

The spectra of the PANI films containing 5 and 40\% HPMC (Fig. 4B and 4C) contain the characteristic vibrations of PANI and HPMC discussed previously. As expected, the sample PANI_5\%HPMC is especially like pure PANI (Fig. 4A), since this is the majority component, while the sample PANI_40\%HPMC the cellulose vibrations have seemed more evidently.

UV-vis diffuse reflectance spectra of the HPMC, PANI, PANI_X\%HPMC samples are shown in Fig. 5A. In comparison to the pristine HPMC membrane which shows a relatively high diffuse reflection in the visible range, the PANI_X\%HPMC films independently of the HPCM loading, exhibits quite low reflection over UV and visible range, as the neat PANI sample, due to great light absorption of this polymer as discussed before. The band gaps of the PANI_X\%HPMC films were estimated by extrapolating the tangent line in the plot of $(F(R) h u)^{\wedge} 2$ against energy (Fig. 5B). The band gap in the case of PANI is in accordance with some previous works.(Farag et al. 2010; Usman et al. 2019) The band gap values increase with HPMC loading. This might be resulted from the weakening of the electronic properties of the hybrid membrane due to the insulating nature of HPMC. Band gaps values for the PANI_X\%HPMC samples are close to each other, coherent with conductivity data.

HPMC membrane shows two broad halos in the range $2 \theta=9-10^{\circ}$ and $2 \theta=20-21^{\circ}$ evidently seen in Fig. 6.(Perfetti et al. 2012) In turn, PANI membrane has two weak diffraction halos in $2 \theta=11^{\circ}$ and $2 \theta=$ $22^{\circ}$ (pointed with magenta arrows), attributed to PVP(Yu et al. 2011) (inset in Fig. 6) and also a shoulder at $2 \theta=25^{\circ}$, typical of PANI(Correa et al. 2012). PANI_5\% HPMC diffractogram is similar to the PANI sample, while PANI_40\% HPMC sample contains HPMC and PANI diffractions overlapped(Lewandowska 2014). These data have showed that the films PANI_X\% HPMC films are amorphous.

Thermogravimetric (TG) (Fig. 7A) analyses were implemented to study the thermal behavior of the films. The thermal decomposition of HPMC could be roughly divided into 3 stages, as seen in the first derivative curve (DTG) (Fig. 7B). The small weight loss from room temperature till $150^{\circ} \mathrm{C}$ was attributed to the elimination of absorbed water. The second stage taking place in the temperature range of $150-450^{\circ} \mathrm{C}$ (DTG peak at ca. $300^{\circ} \mathrm{C}$ ) was designated to the main pyrolysis.(Das et al. 2012) In higher temperature (DTG peak at ca. $550^{\circ} \mathrm{C}$ ) took a further decarboxylation and complete carbonization. PANI and PANI_5\%HPMC thermograms are similar and show four main steps of weight loss. The first one begins at 
room temperature and continues until $150^{\circ} \mathrm{C}$ (gray rectangle) due to the loss of water(Peřinka et al. 2014) and oligomers(Feng et al. 2013). The mass loss in the temperature range of $\sim 150-350^{\circ} \mathrm{C}$ (pointed with black arrow) is due mainly to the elimination of PANI dopant. The two-step weight loss seen in DTG at around $420^{\circ} \mathrm{C}$ (blue rectangle) is a result of the PVP(Ghosh et al. 1999) degradation present in both samples. After $500{ }^{\circ} \mathrm{C}$ (rose rectangle) occurs the degradation of PANI backbone(Peřinka et al. 2014) and HPMC in the case of the PANI_5\%HPMC sample. PANI_40\%HPMC has a thermal behavior like HPMC from $30^{\circ} \mathrm{C}$ till $350^{\circ} \mathrm{C}$, however at higher temperature seems that the decomposition of PVP, PANI, and HPMC occurs in one step observed at $410^{\circ} \mathrm{C}$, indicating good miscibility of all components. The addition of 40 $w t \%$ of HPMC increases the thermal stability of the PANI film.

The glass transition temperatures $(\mathrm{Tg})$ were measured using dynamic mechanical analysis (DMA). Although there are several thermal techniques available to make Tg measurements, by far DMA is the most sensitive technique(2014). Tg has been obtained respectively at the maximum tan $\delta$ peak curves (Fig. 8). The glass transition temperature of PANI is seen at $186^{\circ} \mathrm{C}$. This transition can be understood as the thermal motion of individual chains segments along the polymer backbone. This temperature dropped to $179{ }^{\circ} \mathrm{C}$ when HPMC is added.(Farag et al. 2010) Such an effect can be attributed to the presence of cellulose derivative in the PANI matrix, which increases the mobility of polymer chains and so as a result, the transition happened at the lower temperatures.

The effect of HPMC on the mechanical properties of the neat polyaniline film was evaluated by tensile tests. The stress-straincurves of the films are illustrated in Fig. 3S (supplementary material). From these data, the tensile strength (TS) and elongation at break were calculated (Table 3) and they are shown in Fig. 9. Tensile strength at break measures the maximum stress that a specimen can withstand while being stretched before breaking, while elongation at break measures how much bending and shaping a material can withstand without breaking. HPMC film has the highest tensile strength and elongation, in agreement with literature data(Bilbao-Sainz et al. 2011; Akhtar et al. 2013). On the other hand, PANI shows the lowest TS and elongation, indicating that this film exhibits brittle character. As HPMC is added, independently of the percentage, TS and E\% increase, indicating the films becomes more resistant. In addition, the elastic deformation of both samples containing HPCM is higher than that of the neat PANI film.

Table 3

Tensile strength and elongation of the PANI, PANI_x\%HPMC and HPMC films

\begin{tabular}{|lll|}
\hline Sample & Tensile strength / MPa & Elongation / \% \\
\hline HPMC & $55.7 \pm 3.16$ & $0.167 \pm 0.015$ \\
\hline PANI & $5.11 \pm 0.42$ & $0.018 \pm 0.002$ \\
\hline PANI_5\%HPMC & $9.16 \pm 0.08$ & $0.075 \pm 0.003$ \\
\hline PANI_40\%HPMC & $8.40 \pm 0.24$ & $0.101 \pm 0.006$ \\
\hline
\end{tabular}


Cyclic voltammetry was used to monitor the electroactivity of polyaniline in the films (Fig. 10). PANI (green) and PANI_5\%HPMC (red) voltammograms are quite similar, which is the typical response of the conducting polymer. Two redox processes are seen, the first anodic peak observed at $0.34 \mathrm{~V}$, designated as P1, corresponding the transformation of leucoemeraldine form to emeraldine form of polyaniline. The second one (P2) around $0.57 \mathrm{~V}$ corresponds to the transformation of emeraldine form to pernigraniline form of polyaniline(Deshmukh et al. 2013). On the other hand, due the higher loading of HPMC, an insulating polymer, the electroactivity response is decreased in the PANI_40\%HPMC sample.

\section{Conclusion}

In summary, this work presented a remarkably simple method of preparing self-supported films based on PANI and HPMC. The use of an aqueous solution of PANI was the distinctive aspect of this preparation, which permitted the complete miscibility among the components. All hybrid films (HPMC + PANI) had electrical conductivity in the order of $10^{-2}-10^{-3} \mathrm{~S} \mathrm{~cm}^{-1}$ and the typical electroactivity of the PANI, despite the insulating feature of HPMC. The addition of HPMC in the pristine PAN resulted in improved mechanical properties that can be seen through the tensile tests performed. The formation of cellulose hybrid films with conducting polymer can open new horizons in the field of smart paper technology and can be used in developing flexible electrochemical sensors.

\section{Declarations}

\section{Funding}

This study was financed in part by the Coordenação de Aperfeiçoamento de Pessoal de Nível Superior Brasil (CAPES) - Finance Code 001. The authors gratefully acknowledge the financial support from FAPESP (Grant Numbers 2014/23065-3 and 2018/20826-4).

\section{Competing Interests}

The authors declare that they have no known competing financial interests or personal relationships that could have appeared to influence the work reported in this paper.

\section{Author Contributions}




\begin{tabular}{|c|c|c|c|c|}
\hline & $\begin{array}{l}\text { Study } \\
\text { Conception }\end{array}$ & $\begin{array}{l}\text { Data collections and } \\
\text { analysis }\end{array}$ & Supervision & $\begin{array}{l}\text { First draft of the } \\
\text { manuscript }\end{array}$ \\
\hline Vinicius C. Maeda & & $\mathrm{x}$ & & $\mathrm{x}$ \\
\hline Cintia M. Correa & & $\mathrm{x}$ & & $\mathrm{x}$ \\
\hline $\begin{array}{l}\text { Marcos H. M. O. Otsuka } \\
\text { Hamanaka }\end{array}$ & & $x$ & & $x$ \\
\hline Viviane N. Hamanaka & & $x$ & $x$ & $x$ \\
\hline Celso Molina & $x$ & $x$ & & \\
\hline Fernanda Ferraz Camilo & $\mathrm{x}$ & $\mathrm{x}$ & $\mathrm{x}$ & $\mathrm{x}$ \\
\hline
\end{tabular}

All authors read and approved the final manuscript.

\section{References}

1. Akhtar M-J, Jacquot M, Jamshidian M, et al (2013) Fabrication and physicochemical characterization of HPMC films with commercial plant extract: Influence of light and film composition. Food Hydrocoll 31:420-427. https://doi.org/10.1016/j.foodhyd.2012.10.008

2. Bhattacharya A, De A (1996) Conducting composites of polypyrrole and polyaniline a review. Prog Solid State Chem 24:141-181. https://doi.org/10.1016/0079-6786(96)00002-7

3. Bhatti HS, Kumar S, Singh K, Kavita (2013) Structural and optical characterization of hydroxy-propyl methyl cellulose-capped ZnO nanorods. J Mater Sci 48:5536-5542. https://doi.org/10.1007/s10853013-7348-z

4. Bilbao-Sainz C, Bras J, Williams T, et al (2011) HPMC reinforced with different cellulose nanoparticles. Carbohydr Polym 86:1549-1557. https://doi.org/10.1016/j.carbpol.2011.06.060

5. Boeva ZA, Sergeyev VG (2014) Polyaniline: Synthesis, properties, and application. Polym Sci Ser C 56:144-153. https://doi.org/10.1134/S1811238214010032

6. Cho MS, Park SY, Hwang JY, Choi HJ (2004) Synthesis and electrical properties of polymer composites with polyaniline nanoparticles. Mater Sci Eng C 24:15-18.

https://doi.org/10.1016/j.msec.2003.09.003

7. Correa CM, Faez R, Bizeto MA, Camilo FF (2012) One-pot synthesis of a polyaniline-silver nanocomposite prepared in ionic liquid. RSC Adv 2:3088. https://doi.org/10.1039/c2ra00992g

8. da S. Oliveira R, Bizeto MA, Camilo FF (2018) Production of self-supported conductive films based on cellulose, polyaniline and silver nanoparticles. Carbohydr Polym 199:84-91. https://doi.org/10.1016/j.carbpol.2018.06.049

9. Das R, Panda AB, Pal S (2012) Synthesis and characterization of a novel polymeric hydrogel based on hydroxypropyl methyl cellulose grafted with polyacrylamide. Cellulose 19:933-945. https://doi.org/10.1007/s10570-012-9692-6 
10. Deshmukh PR, Shinde NM, Patil SV, et al (2013) Supercapacitive behavior of polyaniline thin films deposited on fluorine doped tin oxide (FTO) substrates by microwave-assisted chemical route. Chem Eng J 223:572-577. https://doi.org/10.1016/j.cej.2013.03.056

11. Deshpande PP, Jadhav NG, Gelling VJ, Sazou D (2014) Conducting polymers for corrosion protection: a review. J Coatings Technol Res 11:473-494. https://doi.org/10.1007/s11998-014-95867

12. Fahs A, Brogly M, Bistac S, Schmitt M (2010) Hydroxypropyl methylcellulose (HPMC) formulated films: Relevance to adhesion and friction surface properties. Carbohydr Polym 80:105-114. https://doi.org/10.1016/j.carbpol.2009.10.071

13. Farag AAM, Ashery A, Rafea MA (2010) Optical dispersion and electronic transition characterizations of spin coated polyaniline thin films. Synth Met 160:156-161. https://doi.org/10.1016/j.synthmet.2009.10.024

14. Feng $X$, Zhang $Y$, Yan Z, et al (2013) Self-degradable template synthesis of polyaniline nanotubes and their high performance in the detection of dopamine. J Mater Chem A 1:9775. https://doi.org/10.1039/c3ta11856h

15. Furst A, Moore RE (1957) Reductions with Hydrazine Hydrate Catalyzed by Raney Nickel. II. Aromatic Nitro Compounds to Intermediate Products 1. J Am Chem Soc 79:5492-5493. https://doi.org/10.1021/ja01577a044

16. Ghosh P, Chakrabarti A, Siddhanta SK (1999) Studies on stable aqueous polyaniline prepared with the use of polyacrylamide as the water soluble support polymer. Eur Polym J 35:803-813. https://doi.org/10.1016/S0014-3057(98)00065-2

17. Hong X, Liu Y, Li Y, et al (2020) Application Progress of Polyaniline, Polypyrrole and Polythiophene in Lithium-Sulfur Batteries. Polymers (Basel) 12:331. https://doi.org/10.3390/polym12020331

18. Hussin H, Gan S-N, Phang S-W (2021) Effect of functional groups in the PAni-cellulose derivativesbased sensor in hydrazine detection. Polym Bull. https://doi.org/10.1007/s00289-021-03589-x

19. Hussin H, Gan SN, Mohamad S, Phang SW (2017) Synthesis of water-soluble polyaniline by using different types of cellulose derivatives. Polym Polym Compos 25:515-520. https://doi.org/10.1177/096739111702500702

20. Hyodo K (1994) Electrochromism of conducting polymers. Electrochim Acta 39:265-272. https://doi.org/10.1016/0013-4686(94)80062-6

21. Kelly FM, Johnston JH, Borrmann T, Richardson MJ (2007) Functionalised Hybrid Materials of Conducting Polymers with Individual Fibres of Cellulose. Eur J Inorg Chem 2007:5571-5577. https://doi.org/10.1002/ejic.200700608

22. Kim H, Yi J-Y, Kim B-G, et al (2020) Development of cellulose-based conductive fabrics with electrical conductivity and flexibility. PLoS One 15:e0233952. https://doi.org/10.1371/journal.pone.0233952

23. Koczkur KM, Mourdikoudis S, Polavarapu L, Skrabalak SE (2015) Polyvinylpyrrolidone (PVP) in nanoparticle synthesis. Dalt Trans 44:17883-17905. https://doi.org/10.1039/C5DT02964C 
24. Lewandowska K (2014) MISCIBILITY AND INTERACTIONS IN CHITOSAN AND POLYACRYLAMIDE MIXTURES. Prog Chem Appl Chitin its Deriv 19:65-71. https://doi.org/10.15259/PCACD.19.07

25. Liu L, Grunlan JC (2007) Clay Assisted Dispersion of Carbon Nanotubes in Conductive Epoxy Nanocomposites. Adv Funct Mater 17:2343-2348. https://doi.org/10.1002/adfm.200600785

26. Perfetti G, Alphazan T, Wildeboer WJ, Meesters GMH (2012) Thermo-physical characterization of Pharmacoat ${ }^{\circledR}$ 603, Pharmacoat ${ }^{\circledR} 615$ and Mowiol® 4-98. J Therm Anal Calorim 109:203-215. https://doi.org/10.1007/s10973-011-1664-9

27. Peřinka N, Držková M, Hajná M, et al (2014) Thermal analysis of polyaniline poly(N-vinylpyrrolidone)stabilized dispersions. J Therm Anal Calorim 116:589-595. https://doi.org/10.1007/s10973-0143667-9

28. Snook GA, Kao P, Best AS (2011) Conducting-polymer-based supercapacitor devices and electrodes. J Power Sources 196:1-12. https://doi.org/10.1016/j.jpowsour.2010.06.084

29. Somani PR (2003) Synthesis and characterization of polyaniline dispersions. Mater Chem Phys 77:81-85. https://doi.org/10.1016/S0254-0584(01)00579-X

30. Stejskal J, Sapurina I (2005) Polyaniline: Thin films and colloidal dispersions (IUPAC Technical Report). Pure Appl Chem 77:815-826. https://doi.org/10.1351/pac200577050815

31. Trchová M, Šeděnková I, Morávková Z, Stejskal J (2014) Conducting polymer and ionic liquid: Improved thermal stability of the material - A spectroscopic study. Polym Degrad Stab 109:27-32. https://doi.org/10.1016/j.polymdegradstab.2014.06.012

32. Usman F, Dennis JO, Seong KC, et al (2019) Synthesis and characterisation of a ternary composite of polyaniline, reduced graphene-oxide and chitosan with reduced optical band gap and stable aqueous dispersibility. Results Phys 15:102690. https://doi.org/10.1016/j.rinp.2019.102690

33. Wrona M, Cran MJ, Nerín C, Bigger SW (2017) Development and characterisation of HPMC films containing PLA nanoparticles loaded with green tea extract for food packaging applications. Carbohydr Polym 156:108-117. https://doi.org/10.1016/j.carbpol.2016.08.094

34. Yu D-G, Zhu, Branford-White, et al (2011) Solid dispersions in the form of electrospun core-sheath nanofibers. Int J Nanomedicine 6:3271. https://doi.org/10.2147/IJN.S27468

35. (2014) Surface Treatment of Materials for Adhesive Bonding. Elsevier

\section{Figures}



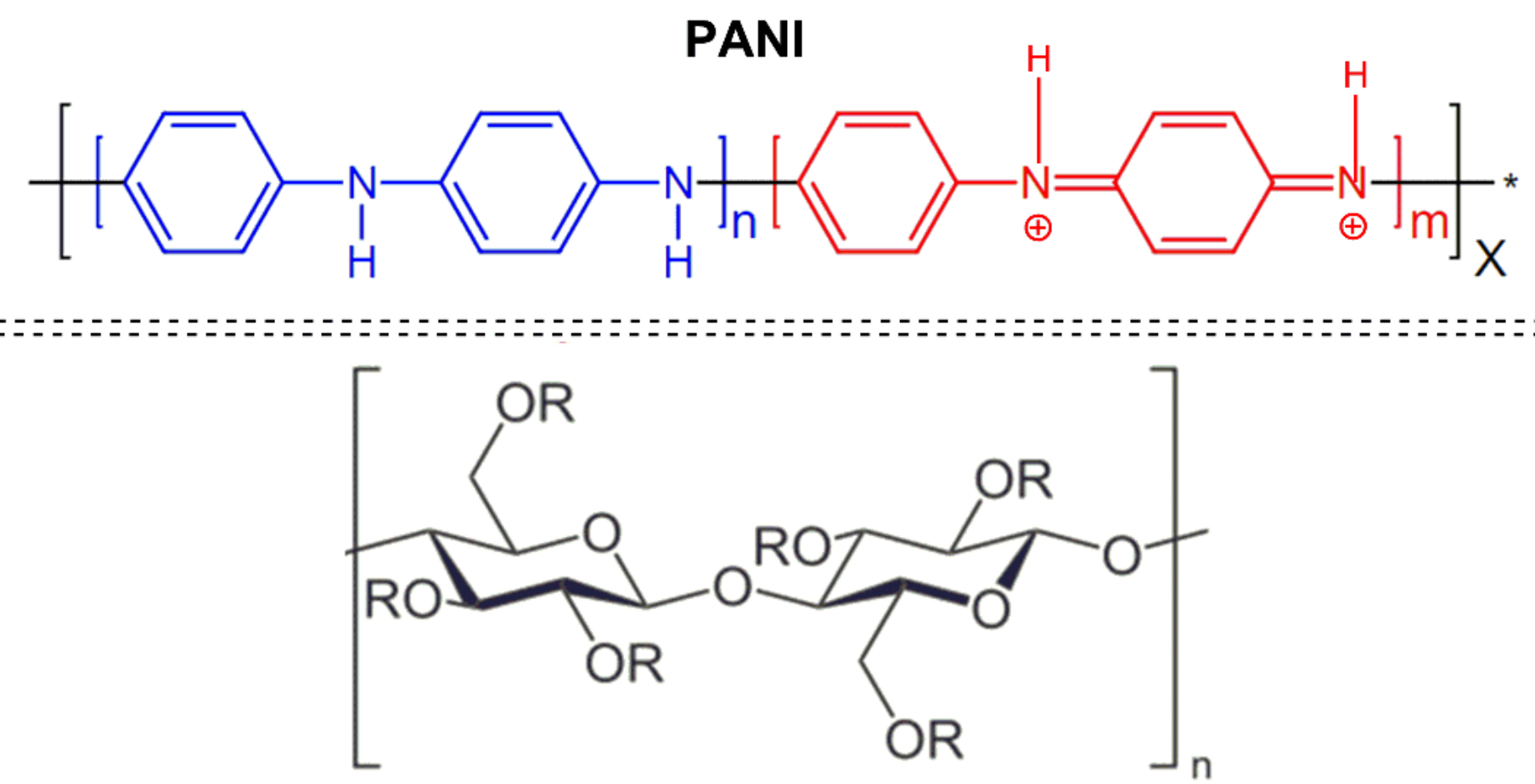

$\mathrm{R}=-\mathrm{H},-\mathrm{CH}_{3},-\mathrm{CH}_{2}-\mathrm{CHOH}-\mathrm{CH}_{3}$

HPMC

Figure 1

PANI and HPMC structures 


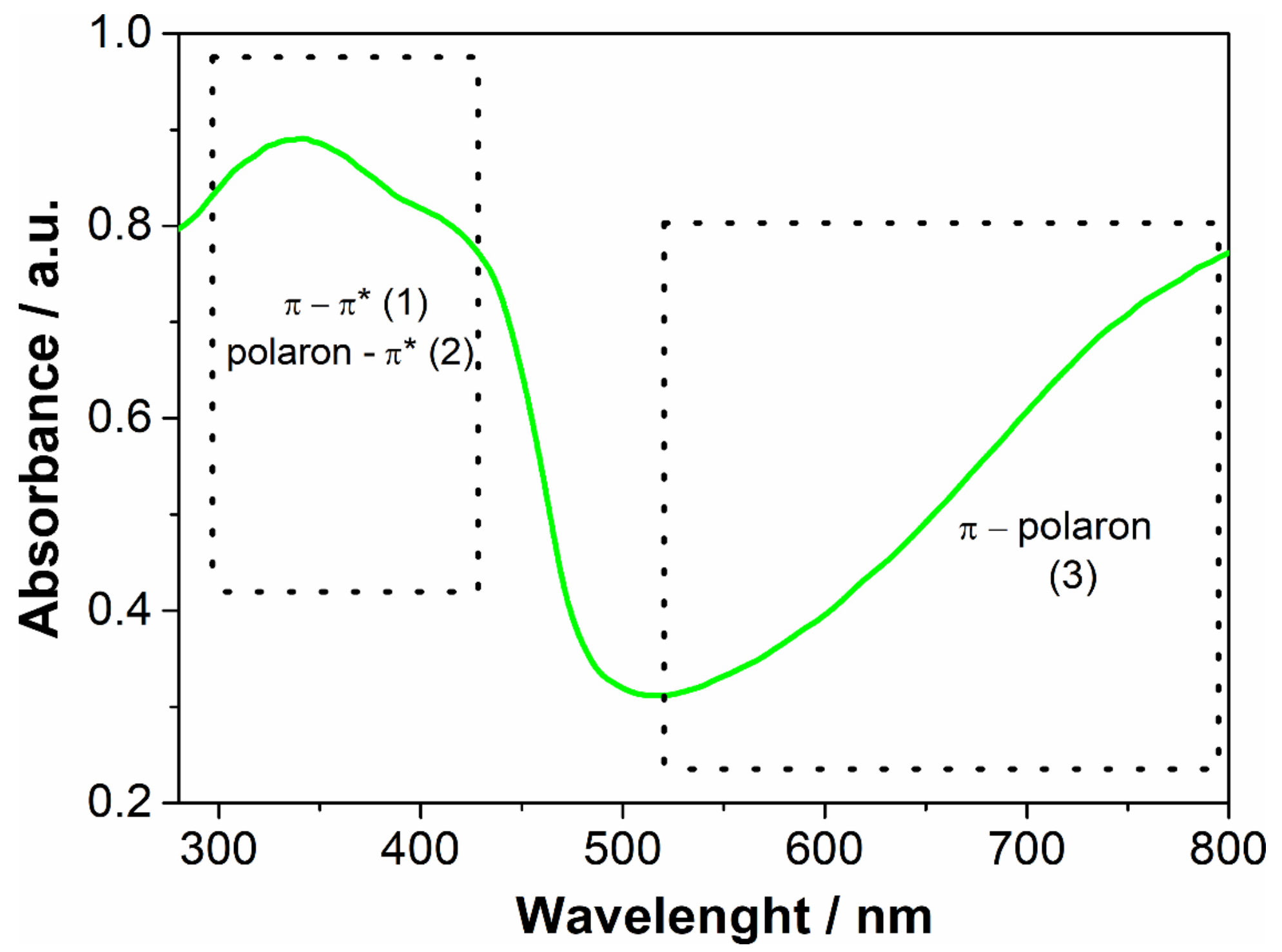

Figure 2

UV-Vis absorbance spectra of polyaniline dispersion 


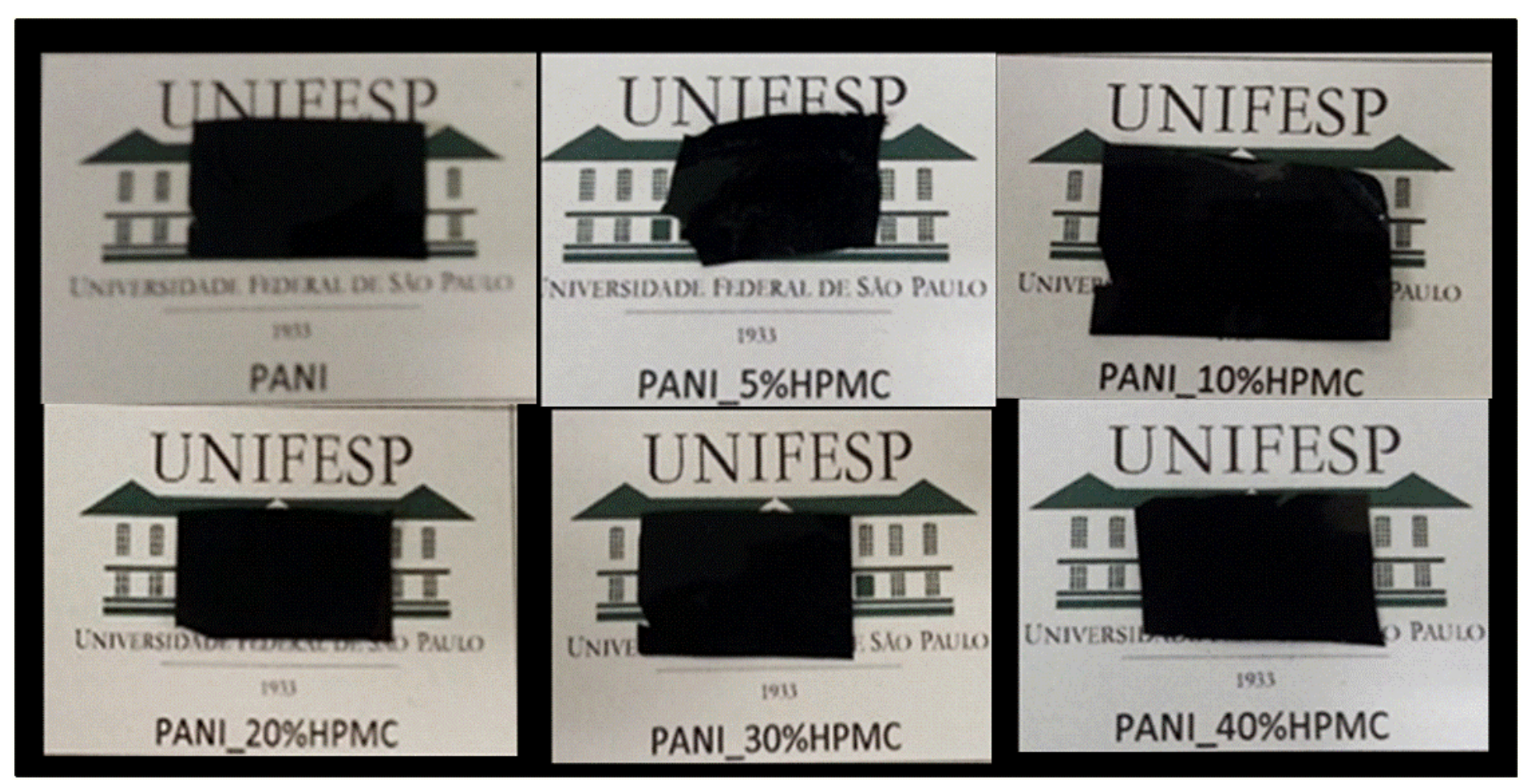

Figure 3

Photos of the HPMC-PANI films 


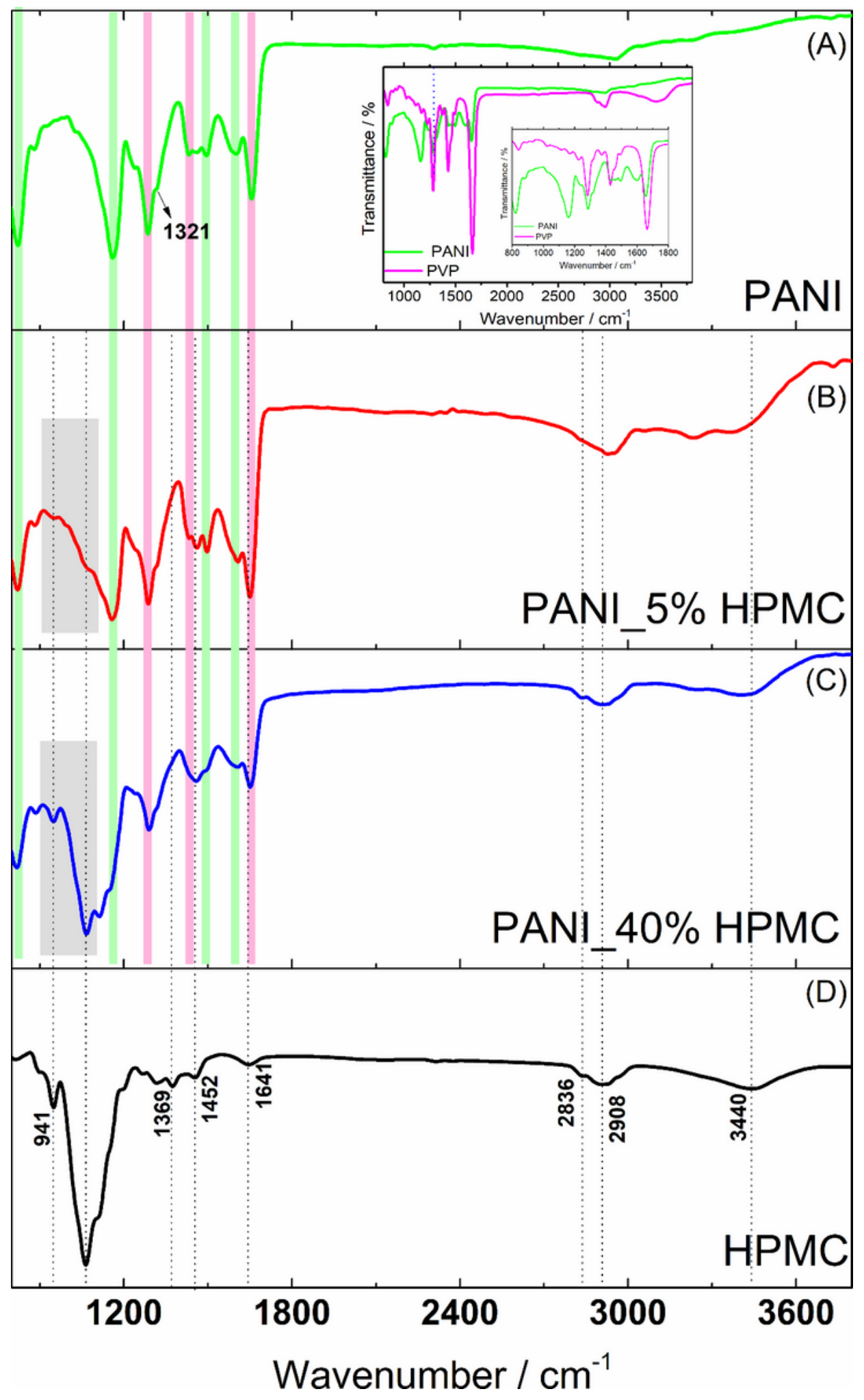

Figure 4

FTIR spectra of PANI (green), PANI_5\%HPMC (red) and PANI_40\%HPMC (blue) and HPMC (black) 

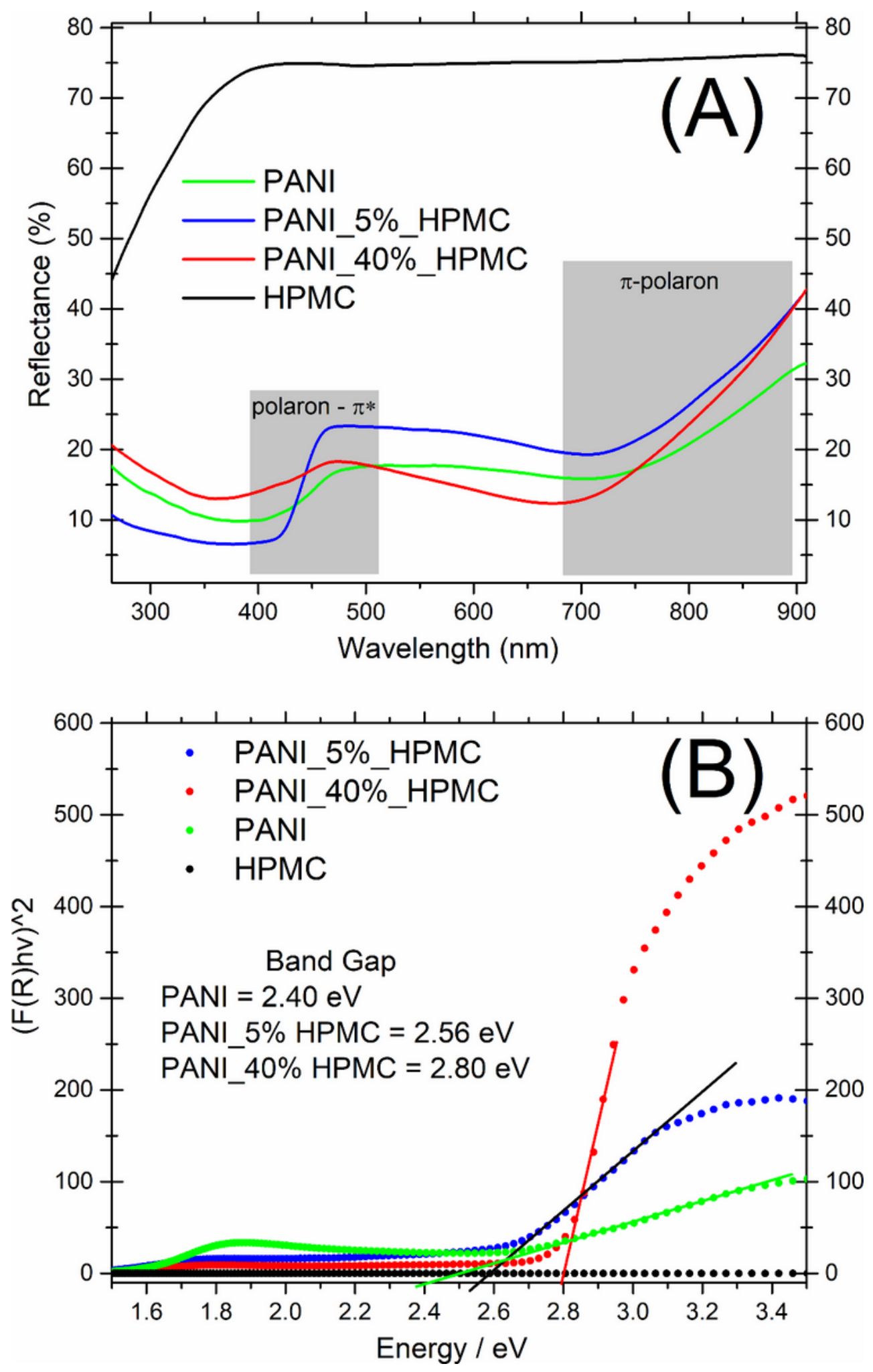

Figure 5

(A) UV-vis diffuse reflectance spectra of PANI (green), PANI_5\%HPMC (red) and PANI_40\%HPMC (blue) and $H P M C($ black) $(B) F(R)$ versus $E$ 


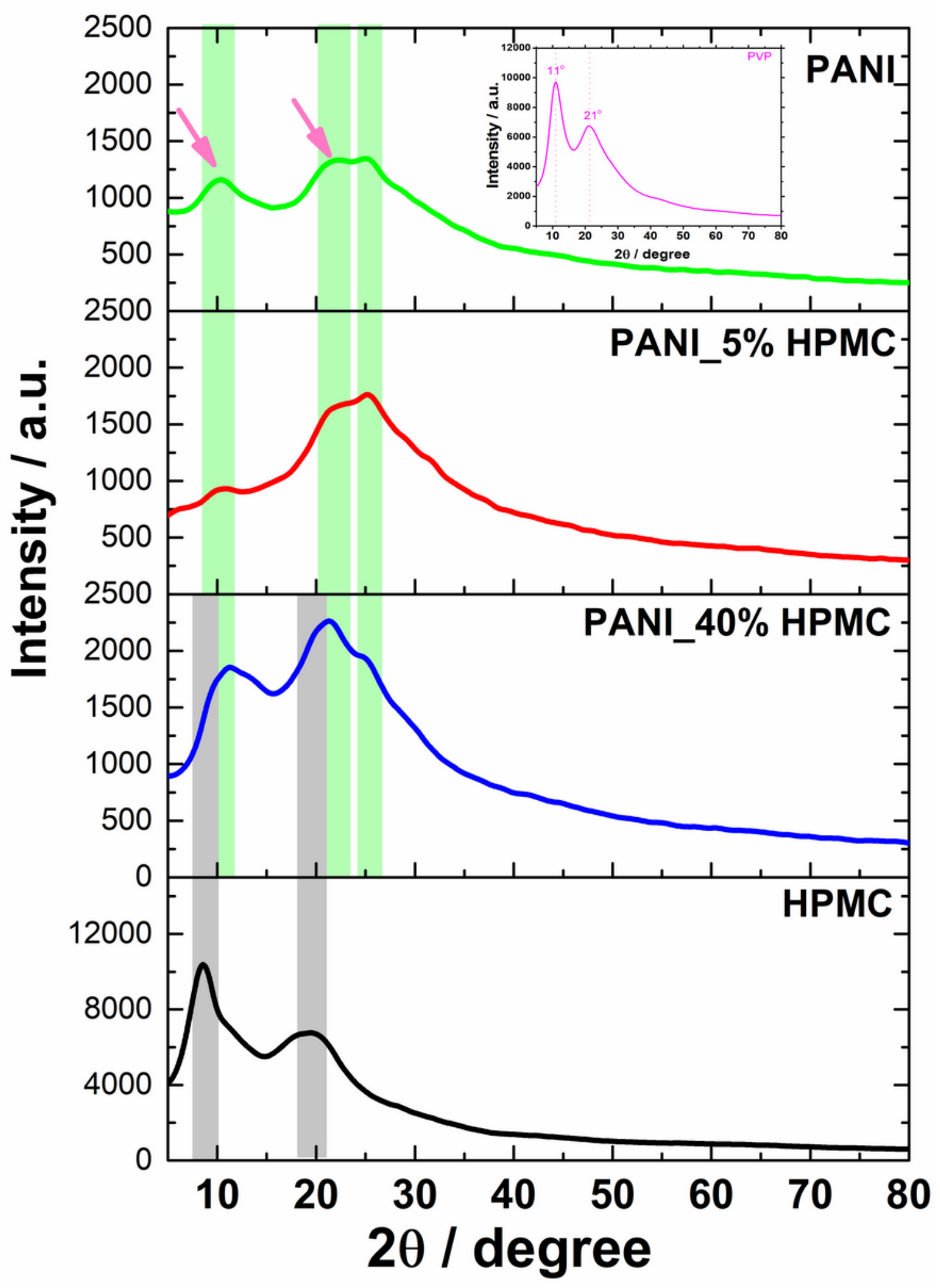

Figure 6

DRX of PANI (green), PANI_5\%HPMC (red) and PANI_40\%HPMC (blue) and HPMC(black) 


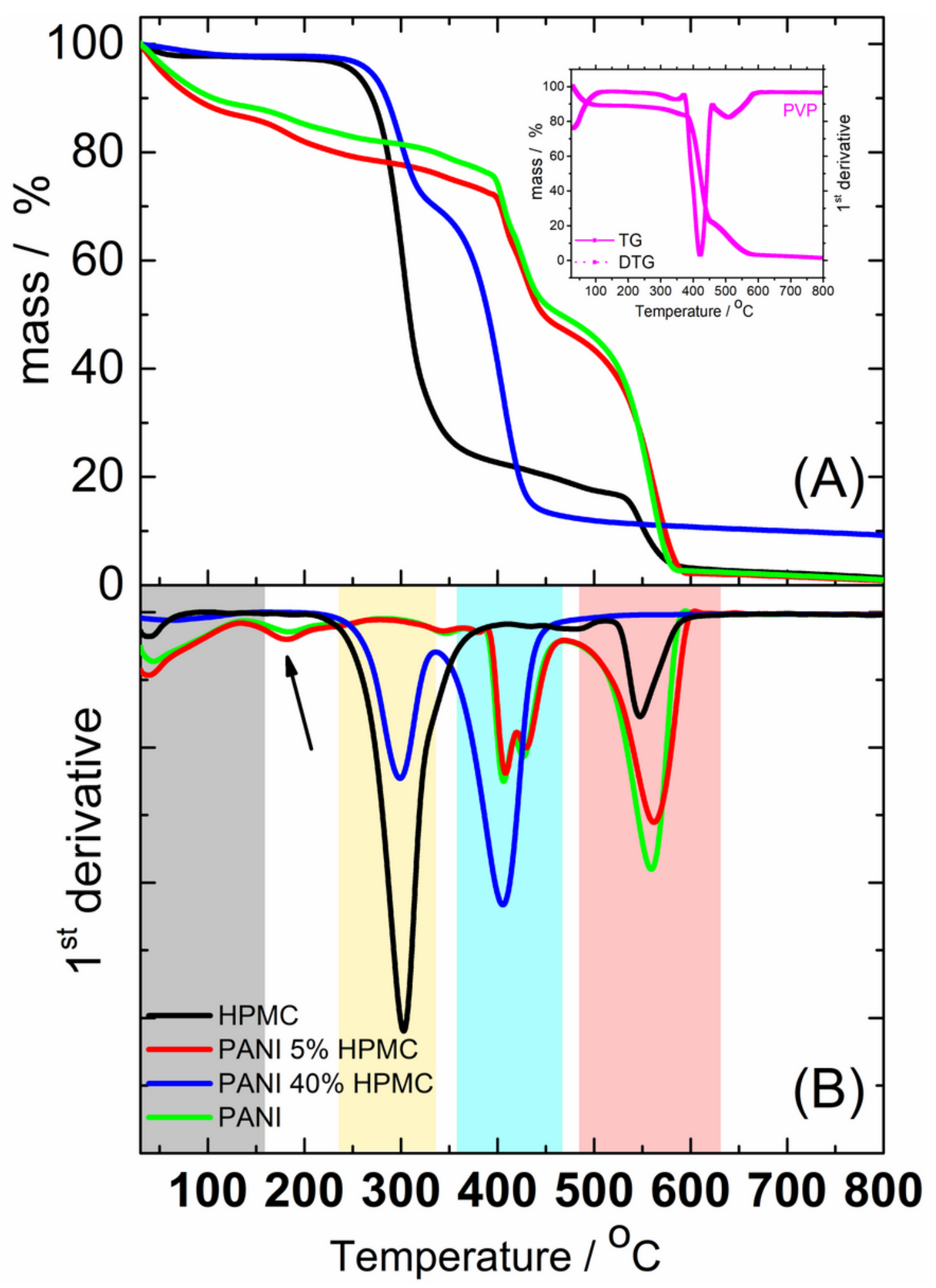

Figure 7

(A) TG curves of HPMC, PANI, PANI_5\%HPMC and PANI_40\%HPMC (B) First derivative 


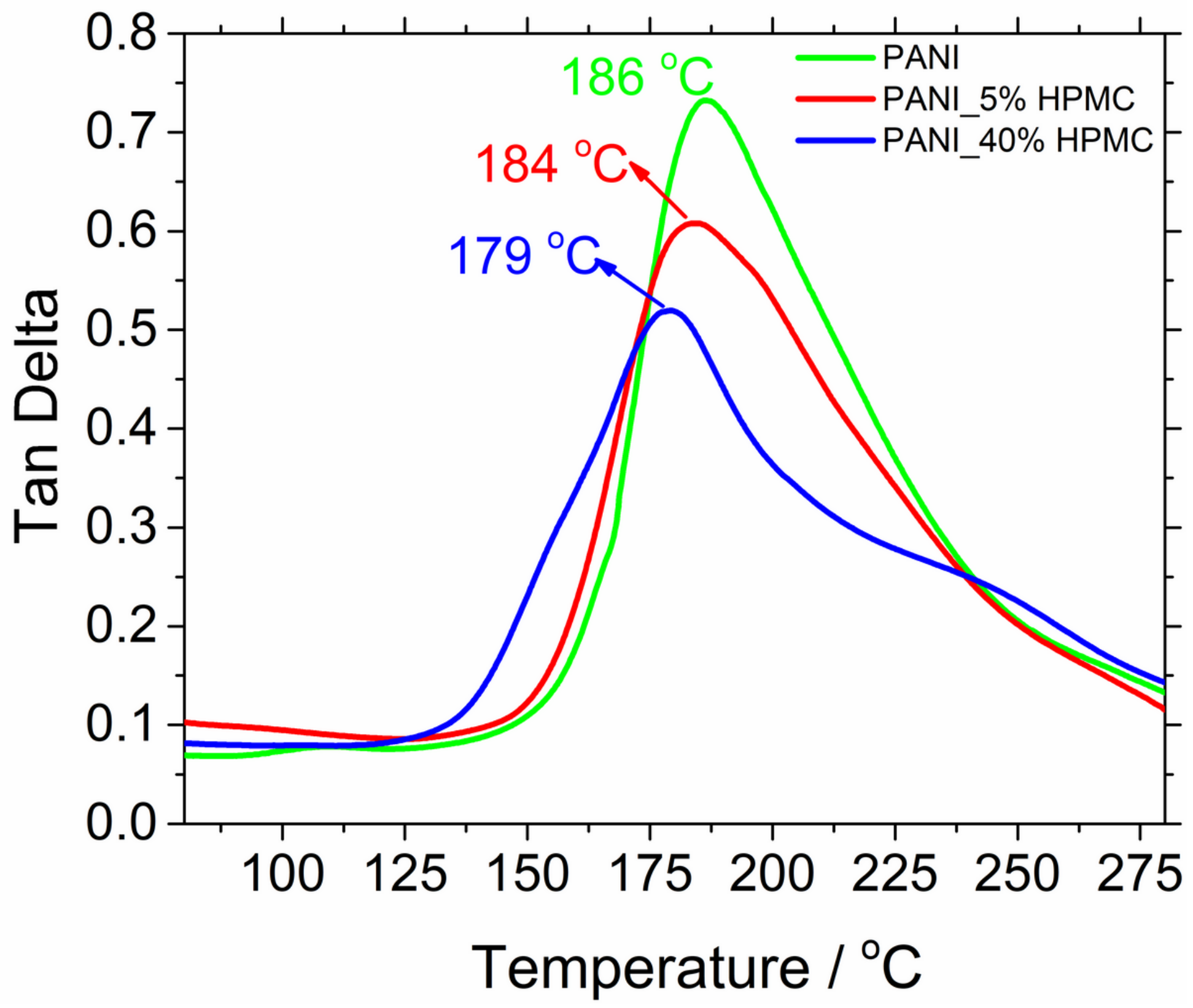

Figure 8

Tangent delta curves of PANI, PANI_5\%HPMC and PANI_40\%HPMC 


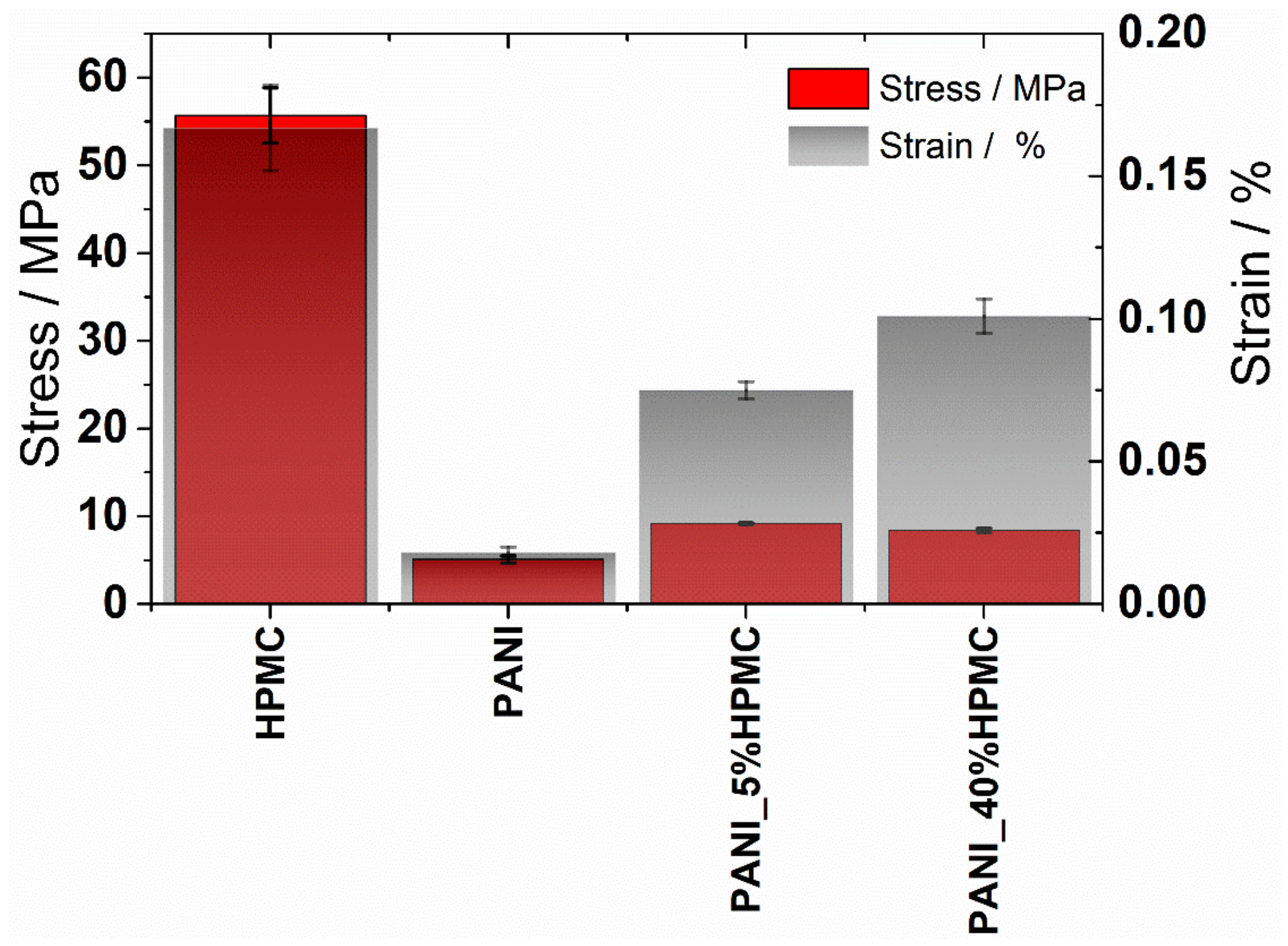

Figure 9

Tensile strength and elongation values of the HPMC, PANI, PANI_5\%HPMC and PANI_40\%HPMC 


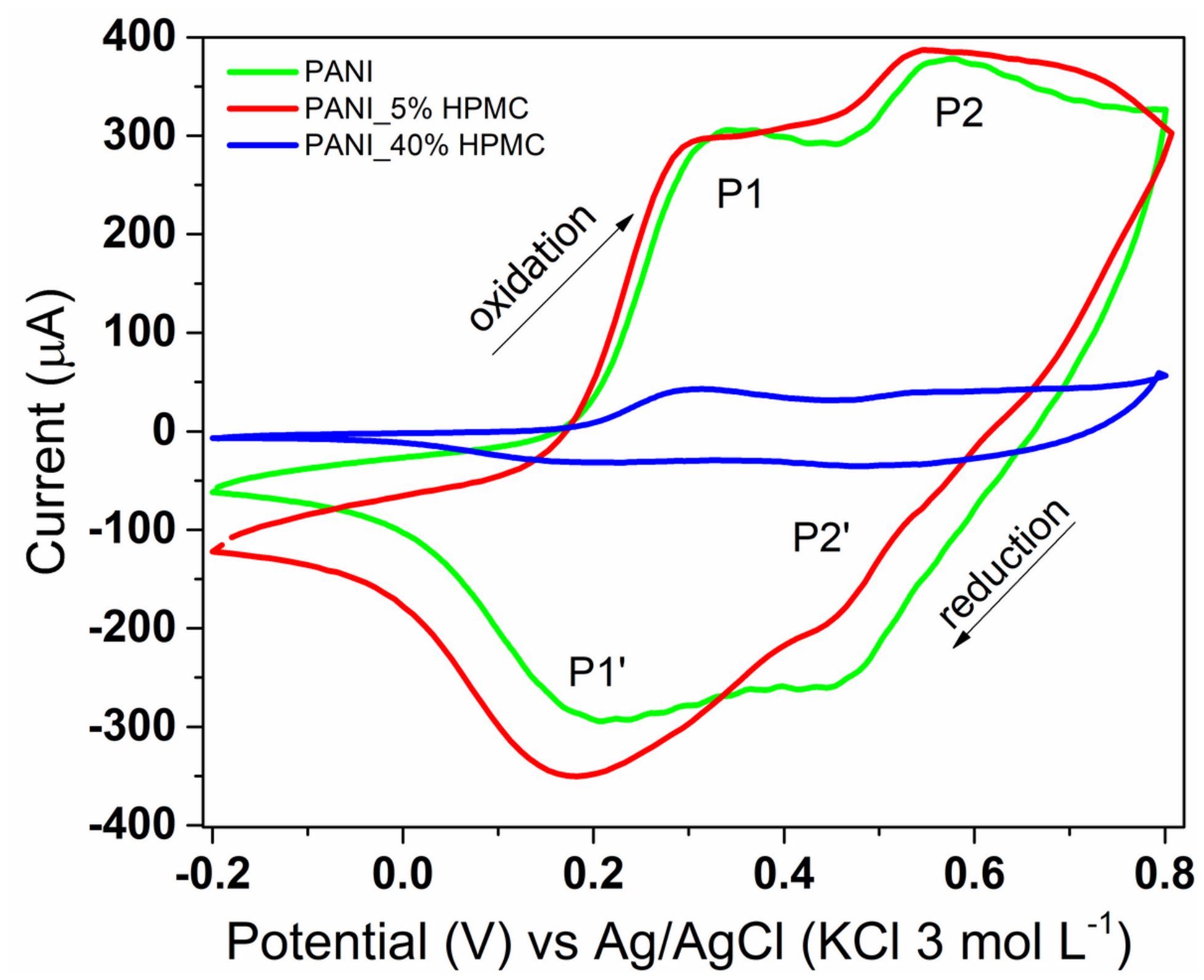

Figure 10

Cyclic voltammograms of PANI (green), PANI_5\%HPMC (red) and PANI_40\%HPMC (blue). Scan rate 100 $\mathrm{mV} \mathrm{s}^{-1}$ in $1.0 \mathrm{M} \mathrm{HCl}$ aqueous solution.

\section{Supplementary Files}

This is a list of supplementary files associated with this preprint. Click to download.

- GraphicalAbstract.tif

- SupplementaryInformation.docx 